\title{
Calculation of Pressure Loss Coefficients in Combining Flows of a Solar Collector using Artificial Neural Networks
}

\author{
Shahzad Yousaf ${ }^{1}$, Imran Shafi ${ }^{2}$, Jamil Ahmad ${ }^{3}$ \\ ${ }^{1,2}$ Department of Mechanical Engineering, CEME NUST Rawalpindi \\ ${ }^{3}$ Department of Computer Engineering, Abasyn University, Islamabad
}

\begin{abstract}
The paper presents a novel technique for determination of loss coefficients due to pressure by use of artificial neural network (ANN) in tee junctions. Geometry and flow parameters are feed into ANN as the inputs for purpose of training the network. Efficacy of the network is demonstrated by comparison of the ANN and experimentally obtained pressure loss coefficients for combining flows in a Tee Junction. Reynolds numbers ranging from 200 to 14000 and discharge ratios varying from minimum to maximum flow for calculation of pressure loss coefficients have been used. Pressure loss coefficients calculated using ANN is compared to the models from literature used in junction flows. The results achieved after the application of ANN agrees reasonably to the experimental values.
\end{abstract}

Keywords-Artificial neural network; pressure loss coefficients for solar collector; combining flow

\section{INTRODUCTION}

Due to industrialization and automation in almost every walk of life, energy consumption is on the rise and scientists are finding new alternatives to conserve the fossils reservoirs. In this regard, the sun is the sole largest source of energy that can provide enough energy to mankind without being explored like conventional energy. If only $0.1 \%$ of solar energy reaching earth at a very low efficiency of $10 \%$ converts into useful energy, it has the potential to generate about 4 times the mankind electricity demands [1]. Solar energy based absorption refrigeration system uses a solar collector to harness the freely available solar energy to heat the working fluid. The hot working fluid circulates in the thermal loop of the cycle and runs absorption/desorption cycles. The efficiency of the solar refrigeration is highly dependent upon the efficiency of solar collector [2]. Efficiency of the system can be increased considerably through an efficient solar collector design. Absorption refrigeration and solar collector systems are shown in Fig. 1 and 2, respectively.

The solar collector has a separate manifold for inflow and outflow. A side pipe identified in this work as riser connects both these manifolds in a parallel way such that an array of pipes is made. In a solar collector, loss of pressure occurs when working fluid flows through its pipes. These losses can be classified as minor and major losses. The major losses occur due to frictional resistance in the flow of fluid while the minor losses occur due to change in momentum of the fluid due to some restrictions in its way. Minor losses are not always lower than the major losses e.g. in the event of solar collector where riser tubes are connected in an array of few hundred tubes adding much higher resistances to flow of the working fluid and hence the momentum loss in the fluid flow occurs. Such situations decrease the efficiency of the solar collectors but proper designing of tee junction may avoid the situation and the system performance increases as a whole.

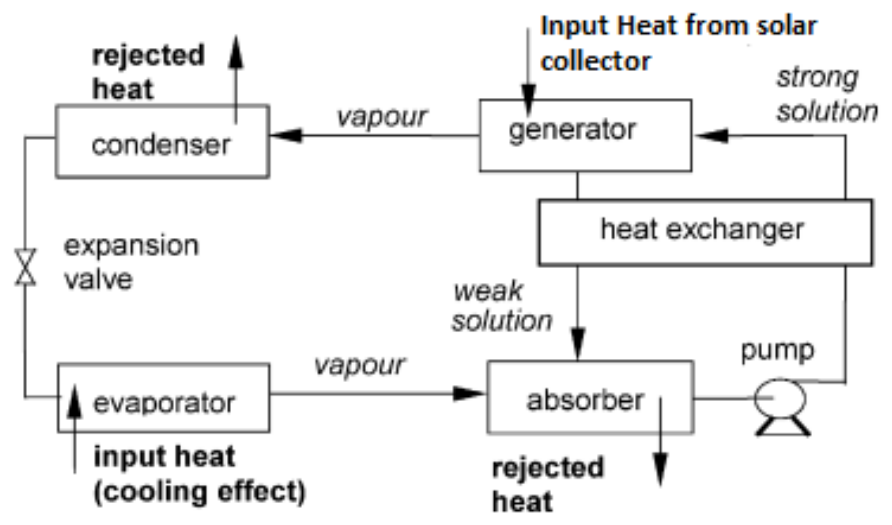

Fig. 1. Solar absorption collector with solar collector as an integral part.

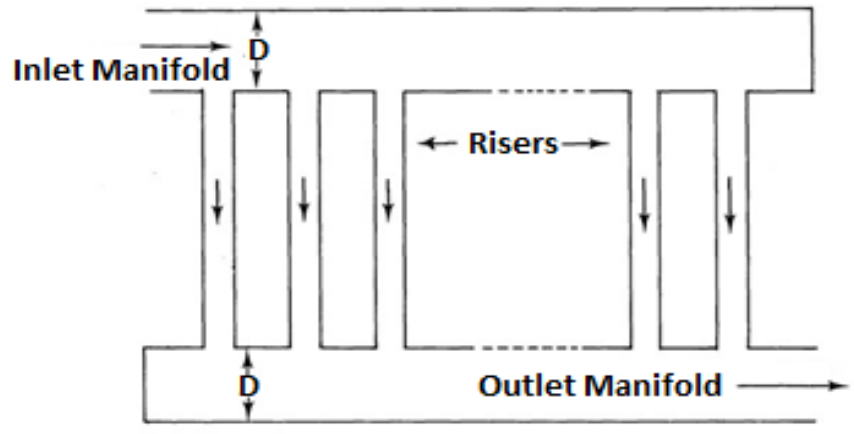

Fig. 2. Geometry of solar collector.

Back Propagation based artificial neural network, due to its guaranteed conversion in solutions of nonlinear equations, is put in use in this work. The multi-input and output nature of ANN and its less computational cost make it first choice for nonlinear equations solution [3]. 


\section{LITERATURE REVIEW}

Pressure loss coefficients (PLC) are ratio of stagnation pressure difference of upstream and downstream pipe in riser/straight pipes. It represents the energy loss in flow between upstream and downstream. Therefore, there will be two loss coefficients, one for riser and second for the straight pipe. Mathematically it is given by the following formula:

$$
k_{\mathrm{i}}=\Delta \mathrm{p}_{\mathrm{i}}\left[\left(\frac{\rho \mathrm{V}^{2}}{2}\right)\right]^{-1}
$$

Whereas subscript $i=s t, s$

$\Delta P=$ Loss of stagnation pressure in ith pipe

$\rho=$ Heat transfer fluid density

$V=$ Velocity of flow in combined pipe

$K_{s t}=$ PLC in straight pipe

$K_{s}=$ PLC in riser

In combining flow, energy loss in flow is dependent on flow ratios in riser $\left(Q_{S} / Q_{C}\right)$ and straight pipes $\left(Q_{s t} / Q_{c}\right)$ [15]. According to the frictionless Bernoulli theorem, the velocity and momentum of working fluid decreases as the fluid approaches the junction making an increase in the. But when the effects of frictions are considered at this point, the pressure decreases and hence pressure loss occurs [4]. In a converging flow, the losses in pressure and momentum occur due to fluid mixing from both the legs of the tee junctions as well as due to 90-degree bend at the junction [5].

Pressure loss coefficients are usually calculated by experiments that require waste of resources [6]. Gardle calculates pressure losses due to the geometry of junctions by considering different discharge ratios in both the legs of the tee junctions by using an empirical formula. The empirical formula is not applicable to all types of flows [7]. Through an experimental study for both the combining and diving flow, Bingham and Blair studies the flow distribution and the pressure losses in a tee junction [8]. They developed a single equation from their experimental data. The disadvantage in work of Bingham is that data for dividing and combining flow has been mixed. Hagers investigate the effects of an area ratio of unity on the flow in a tee junction [9]. Flamang takes into account the effects of lateral angle for junction flow along with the area ratios effects [10]. But satisfactory correlation has not been made to all of the flow types in a junction pipe. For unsteady flow in engine manifolds, modeling have been done successfully by assuming that pressure loss in unsteady and steady flow is same [4]. The system of simultaneous equations has been solved by Weitbrecht et al. for flow distribution and pressure loss calculation [11]. For one riser pipe in a solar collector, the system contained 28 nonlinear equations. The work of Jones and Lior does not give many results and not much insight is given about effects of various flow parameters on flow. They investigated pressure losses for tee junctions by developing a discrete model using nonlinear algebraic equations [12]. Bajura and Jones studied different parameters for flow in junctions. Experimental results from their work show that flow distribution in laminar flow differs from that of a high Reynolds number flows [13]. Idelchik and Miller independently studied various parameters like area ratios, discharge ratios for different lateral pipe angles that affects loss coefficients of pressure in flow involving junctions [15], [16]. Both of the studies do not take the effects of Reynolds number into account. On a commercial CFD package, the idea of Weitbrecht et al. [11] has been used by Badar et al. for the estimation of loss in pressure due to change in momentum and flow distribution in a solar collector. He concludes that nonconformity in results and experiments is mainly due to incapability of the CFD package to capture the minute details of flow and boundary conditions that might not depicts the true nature of flow [14]. A comparative study of pressure loss in tee junction and elbows has been performed by Moujaes on Fluent- a CFD commercial software for a fixed discharge ratio of 0.5. Finding of the investigation is that tee junction offers more resistance to the flow through it as compared to elbow [15]. Bassett et al studied tee junction flow in combining and dividing flow. The flow is energized using shock wave for high Reynolds number flow and developed equations for all type of flows in junctions [17]. In [17] the flow reverses as soon as the energizing shock wave diminishes thus affecting the loss coefficients values and also it does not give any specific range of Reynolds number in which the equation holds true. Similarly, Wahab et al used SIMPLE algorithm on CFD package to predict the pressure losses in junction flow [18]. The results achieved are higher than literature results for constant diameter pipes. More recently, Bawa determined numerically the total pressure loss in a solar collector [19]. But no information has been presented regarding loss of pressure in the collector due to geometry of the solar collector under consideration.

\section{PROPOSED METHOD}

We are suggesting a new novel technique, to the best of our knowledge, based upon ANN for evaluation coefficients of pressure loss in combining flow. The ANN evolved after the functioning of the human brain was studied. ANN is nonlinear statistical models. They do not compete in complexity to brain and central nervous system of human. Network is formed when neurons connects to each other through synaptic connections with the ability to convey data through various layers. This network is capable of estimation of energy loss in flow in the form of pressure loss coefficients. These networks are regarded as highly efficient system due to their adaptive nature. In this network, information is transmitted through neurons as by giving them input feed, which is further connected through a specific activation function. Data transmission is done in layers of signals with weights exciting or inhibiting the signal and finally, the output is retrieved in the form of pressure loss coefficients.

ANN performs its function in the following steps (Fig. 3): 


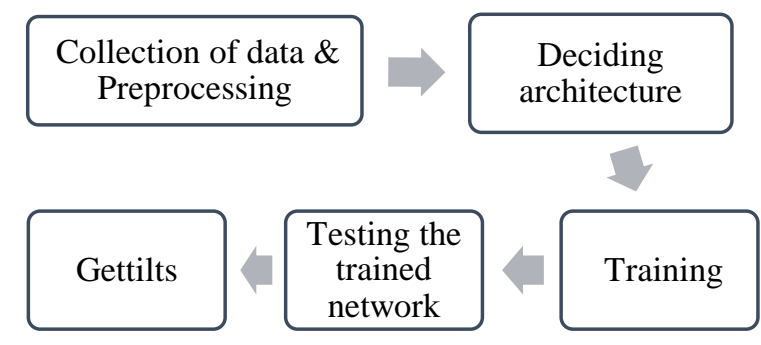

Fig. 3. Design stages of an artificial neural network.

\section{A. Data Collection and Preprocessing}

For training purpose, an artificial neural network needs a set of data. Before the training process begins, data set refinement and preprocessing is done. In the current work, experimental data has been gathered from a tee-junction setup as shown in Fig. 4. Sensors are installed at points a, b and c that records stagnation pressure and from which loss coefficients of pressure are calculated using (1).

Geometry specifications for experimental setup are as under (Table I):

TABLE I. GEOMETERY SPECIFICATION OF TEE JUNCTION SET UP

\begin{tabular}{|l|l|}
\hline Parameter & Specifications \\
\hline Diameter of manifold, D & $16.6 \mathrm{~mm}$ \\
\hline Diameter of riser, d & $7.2 \mathrm{~mm}$ \\
\hline Entry length of inlet pressure sensor, a & $560 \mathrm{~mm}$ \\
\hline Entry length of outlet pressure sensor, b & $990 \mathrm{~mm}$ \\
\hline Length of riser pressure sensor from outlet, c & $17 \mathrm{~mm}$ \\
\hline Riser angle, $\alpha$ & $90^{\circ}$ \\
\hline
\end{tabular}

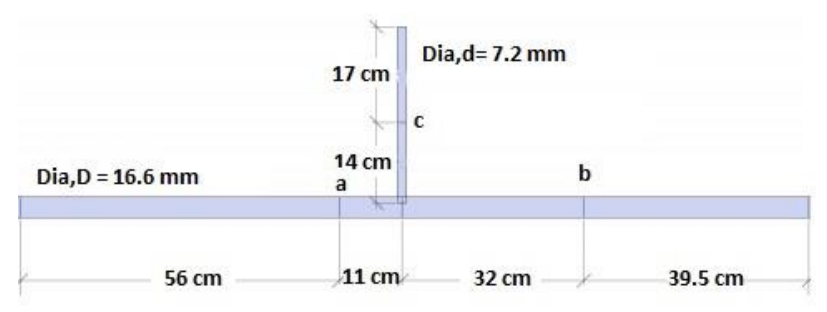

Fig. 4. Geometry specification of tee junction used.

The experimental results obtained are processed for ANN training. It is pertinent to mention that water is used as heat transfer fluid with constant density neglecting the effects of buoyancy.

The 30 features are recorded while performing experiments on the tee junction set up. Among them only relevant features that affect the pressure loss coefficients are selected using Relief algorithms for ANN training [20] as shown in Table II. Feature relevancy obtained after application of relief is shown in Table III.
TABLE II. EXPERIMENTAL CONDITIONS FOR COLLECTION OF DATA

\begin{tabular}{|l|l|l|}
\hline Factors & ISO 9086 Conditions & $\begin{array}{l}\text { Experimental } \\
\text { condition }\end{array}$ \\
\hline $\begin{array}{l}\text { Temperatur } \\
\text { e range }\left({ }^{\circ} \mathrm{C}\right)\end{array}$ & $18-22$ & $18-22$ \\
\hline Fluid & Water or mixture of water/glycol (60/40) & Water \\
\hline
\end{tabular}

TABLE III. FEATURE RELEVANCy OBTAINED After APPLICATION OF RELIEF

\begin{tabular}{l|l}
\hline Name of feature & Score of feature (\%) \\
\hline Penetration depth & 30 \\
Mass flow rate & 20 \\
Volume flow rate & 20 \\
Reynolds number & 12.5 \\
Velocity of flow & 12.5 \\
Entry length & 5 \\
\hline
\end{tabular}

\section{B. Network Architecture Selection}

Architecture selection for training purpose of the network has been done by hit and trial method because there is no fix rule available for network architecture specifications [21]. This work uses a network architecture of 6-30-2 neurons in input-hidden-output layers.

\section{Training}

The selected network is trained using learning rule known as Marquardt-Levenberg back propagation rule. The layers and neurons are interconnected using tan-sigmoid function as an activation function. Training stoppage criterion is also chosen that includes maximum number of epochs, mean square error and time. This training criterion helps in preventing the network from overfitting and thus the ability to predict the unseen conditions improves.

\section{Testing}

The network trained is tested upon the unseen data. The efficacy of the network can be seen when the ANN and experimental data are compared to each other for different situations of flow as shown in the next section.

\section{RESUlTS AND DISCUSSION}

Reynolds number starts from a very low laminar region ( $\operatorname{Re}=200)$ to a very turbulent region $(\operatorname{Re}=14000)$ for the current work. The discharge ratios range from 0 to 1 for combining flow in tee junction. Much focus has been on the laminar flow region due to the scant literature which has been identified by [5], [12], [13], [16]. For combining flows, the junction has two inlets pipes and one outlet pipe. A number of data points are tested and results are plotted in Fig. 5 for both manifold and riser of tee junction.

Fig. 5 shows the variations in loss coefficients due to pressure and its dependency on another non dimensional quantity-Reynolds number. Velocity of fluid in tee junction is kept as low as $.01 \mathrm{~m} / \mathrm{s}$ to $0.2 \mathrm{~m} / \mathrm{s}$ in the laminar flow region. For the case of turbulent region, Reynolds number has been 
kept high so that it may be investigated on a highly turbulent flow and it ranges from 7000 to 14000 in pipe outlet with a lower velocity in combined pipe ranging from $0.3 \mathrm{~m} / \mathrm{s}$ to 0.9 $\mathrm{m} / \mathrm{s}$. In the same figure, the same property i.e. Reynolds number has been studied for side pipe (riser) which is shown by subscript 's'. For side pipe, the values of pressure loss coefficients are higher than straight pipe due to the fact the there is greater loss of pressure resulting from mixing of two the streams as well as from the bending of pipe at an angle of 90 degrees. Few values of pressure loss coefficients are negative for riser portion of the tee junction. This situation arises when the volume flow rate and Reynolds number are kept high in side pipe; the pressure difference becomes negative giving a negative value for loss coefficients. For combining flow, Fig. 5 shows a trend of decrease in values of loss coefficients considerably as the Reynolds number increases.

The second important parameter is flow ratio in both the manifold and riser pipes. The discharge ratios in both the pipes of the tee junction are varying from 0 to a maximum of 1. Fig. 6 shows plot of manifold and riser pipes for the junction flow with respect to discharge ratios for pressure loss coefficients comparison between ANN and experimental values

The observed trend for pressure loss coefficients in manifold is that for increasing discharge ratio the pressure loss coefficients decreases significantly while for the case of riser, it is exactly opposite. The pressure loss coefficients increase as the discharge ratio increases from zero to 1 .

Fig. 5 and 6 shows that proposed method of ANN is following the experimental results for both parameters of Reynolds number and discharge ratios. Few of the models discussed in the literature are used for comparison in Fig. 7, 8 and 9. Fig. 7 shows the comparison of ANN with experimental values, Bassett's [18], Idelchik's [5] and Badar's [16] equations for manifold pressure loss coefficients plotted against the discharge ratios. It is evident that ANN and experimental values are close to each other while the rest are following the trend of decreasing pressure loss coefficients values as the discharge ratio increase from minimum to maximum.
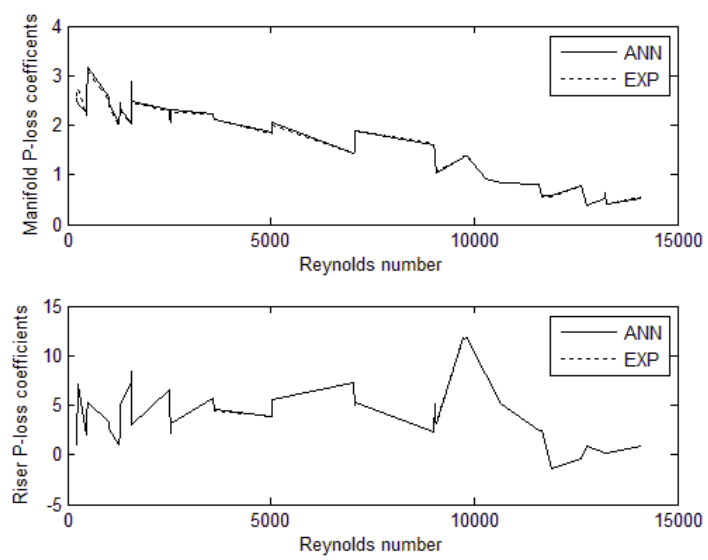

Fig. 5. Pressure Loss coefficient comparison between experiment and ANN for different Reynolds numbers.
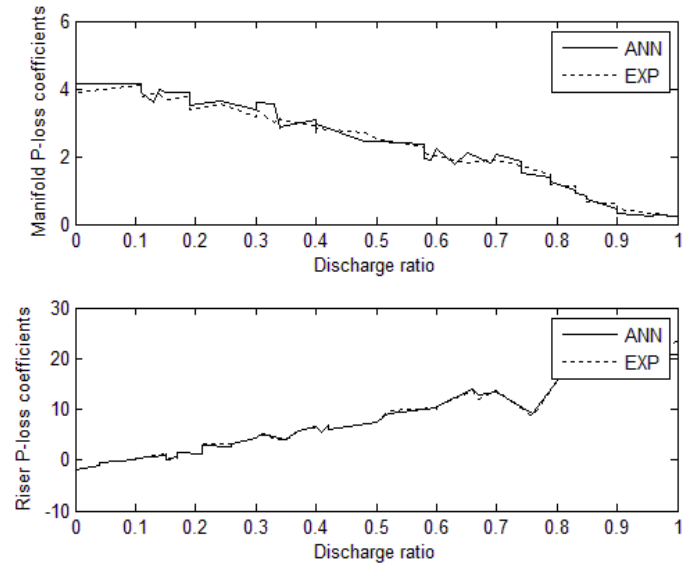

Fig. 6. Pressure loss coefficient comparison between experiment and ANN for different discharge ratios.

In Fig. 9, the comparison has been done for pressure loss coefficients in riser pipe of the tee junction. Here, the literature models and the proposed model along with the experimental values are reasonably close to each other and trend of increasing pressure loss coefficient is followed as the discharge ratio increases in the riser portion of tee junction. In Fig. 8, Badar's equations [16] for the pressure loss coefficient in riser are compared but the trend of experiment and other literature is not followed.

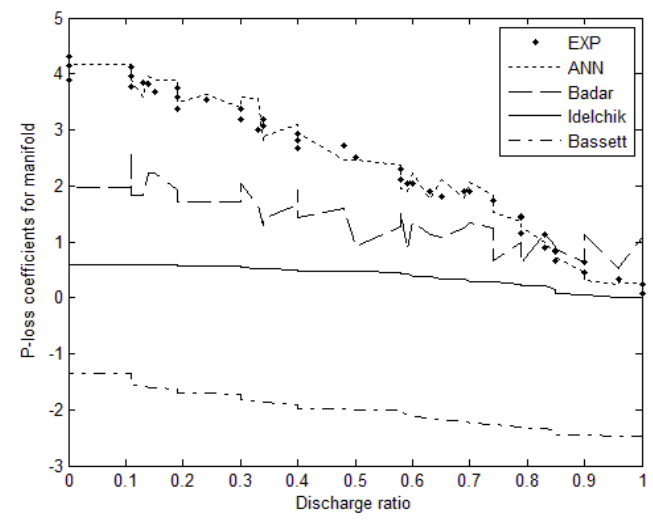

Fig. 7. Literature models comparison in manifold of solar collector's tee junction.

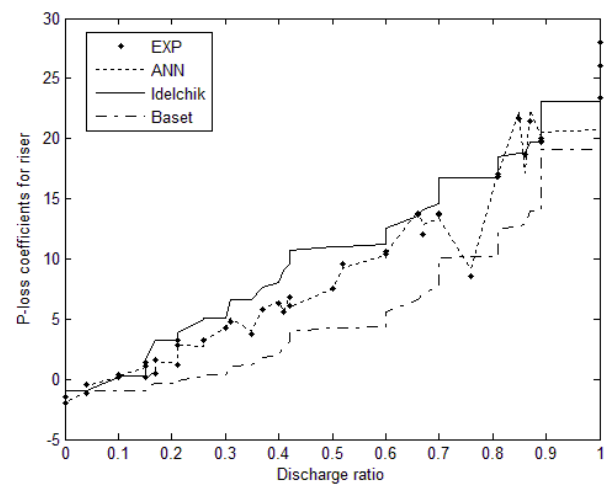

Fig. 8. Literature model comparison for riser of a solar collector's teejunction. 


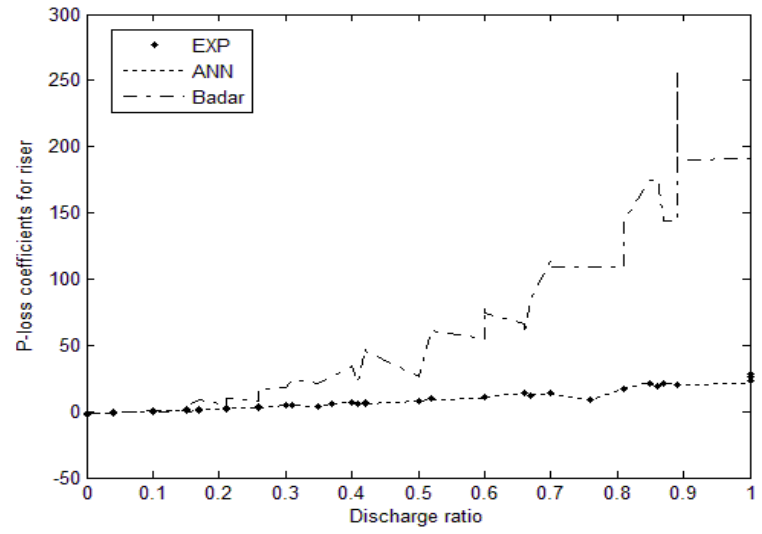

Fig. 9. Literature model comparison for riser of a solar collector's teejunction.

\section{CONCLUSION}

In this paper, effect of Reynolds number along with varying discharge ratio from zero to maximum has been studied for both the riser and manifold of tee junction for combining flow loss coefficients. Loss coefficients due to the pressure change in manifold have lower values then riser pipe due to large volume flow rate and straightness. The general trend observed is that with an increase in Reynolds number and discharge ratio in the manifold, the values of loss coefficients decreases. The relationship for loss coefficients in the riser with discharge ratios and Reynolds number is complex. The values increase with Reynolds number while decreases with discharge ratios in the riser. Plots show that ANN is determining pressure loss coefficients reasonably with an average error value of $4 \%$ in pressure loss coefficient for straight pipe and error value of $2.24 \%$ in side pipe pressure loss coefficient between experimental and proposed method. The ANN model proposed agrees satisfactorily with the experimental values and thus demonstrating the ability to replace the expensive experimental and other analytical techniques requiring high performance and large memory computers.

\section{REFERENCES}

[1] M. Thirugnanasambandam, S. Iniyan, and R. Goic, "A review of solar thermal technologies," Renewable and Sustainable Energy Reviews, vol. 14, no. 1, pp. 312-322, Jan. 2010.

[2] A. Syed et al., "A novel experimental investigation of a solar cooling system in Madrid," International Journal of Refrigeration, vol. 28, no. 6, pp. 859-871, 2005.

[3] A. Azzini, "A new generic approach for neural network design and optimization," PhD, University of Milan, Milan, 2006.
[4] D. E. Winterbone and R. J. Pearson, Design techniques for engine Manifolds: Wave action methods for IC engines. Professional Engineering Publishing, 1999.

[5] I. E. Idelchik and E. Fried, "Handbook of hydraulic resistance: Second edition (book)," Hemisphere Publishing,New York, NY, 1986.

[6] E. Ruus, "Head losses in Wyes and Manifolds," Journal of the Hydraulics Division, vol. 96, no. 3, pp. 593-608, 1970.

[7] Gardel, André. Les pertes de charge dans les écoulements au travers de branchements en té. Éd. de la Soc. du Bulletin Technique de la Suisse Romande, 1957.

[8] J. F. Bingham and G. P. Blair, "An improved branched pipe model for multi-cylinder automotive engine calculations," Proceedings of the Institution of Mechanical Engineers, Part D: Journal of Automobile Engineering, vol. 199, no. 1, pp. 65-77, Jan. 1985.

[9] W. H. Hager, "An approximate treatment of flow in branches and bends," Proceedings of the Institution of Mechanical Engineers, Part C: Journal of Mechanical Engineering Science, vol. 198, no. 1, pp. 63-69, Jan. 1984.

[10] Flamang, P. Studie van de stroming in juncties van uitlaat--systemen van opgeladen dieselmotoren. Diss. PhD thesis, Rijksuniversiteit, Gent, 1989.

[11] V. Weitbrecht, D. Lehmann, and A. Richter, "Flow distribution in solar collectors with laminar flow conditions," Solar Energy, vol. 73, no. 6, pp. 433-441, Dec. 2002.

[12] G. F. Jones and N. Lior, "Flow distribution in manifolded solar collectors with negligible buoyancy effects," Solar Energy, vol. 52, no. 3, pp. 289-300, Mar. 1994.

[13] R. A. Bajura, " A Model for Flow Distribution in Manifolds," Journal of Engineering for Power, vol. 93, no. 1, pp. 7-12, Jan. 1971.

[14] A. Badar, R. Buchholz, Y. Lou, and F. Ziegler, "CFD based analysis of flow distribution in a coaxial vacuum tube solar collector with laminar flow conditions," International Journal of Energy and Environmental Engineering, vol. 3, no. 1, p. 24, 2012.

[15] S. F. Moujaes and S. Deshmukh, "Three-Dimensional CFD Predications and experimental comparison of pressure drop of some common pipe fittings in turbulent flow," vol. 132, no. 2, Aug. 2006

[16] D. S. Miller, "REPIDISCA-Internal flow: A guide to losses in pipe and duct systems," British Hydromechanics Research Association, 1971.

[17] M. Bassett, D. Winterbone and R. Pearson, "Calculation of steady flow pressure loss coefficients for pipe junctions", Proceedings of the Institution of Mechanical Engineers, Part C: Journal of Mechanical Engineering Science, vol. 215, no. 8, pp. 861-881, 2001.

[18] M. Abdulwahhab, N. Kumar, Injeti, and S. F. Dakhil, "Numerical prediction of pressure loss of fluid in a t-junction," International Journal of Energy and Environment, vol. 4, no. 2, pp. 253-264, 2012.

[19] F. Bava and S. Furbo, "A numerical model for pressure drop and flow distribution in a solar collector with u-connected absorber pipes," Solar Energy, vol. 134, pp. 264-272, Sep. 2016

[20] J. Jia, N. Yang, C. Zhang, A. Yue, J. Yang, and D. Zhu, "Objectoriented feature selection of high spatial resolution images using an improved relief algorithm," Mathematical and Computer Modelling, vol. 58, no. 3-4, pp. 619-626, Aug. 2013.

[21] I. Shafi, J. Ahmad, S. I. Shah, and F. M. Kashif, "Computing Deblurred time-frequency distributions using artificial neural networks," Circuits, Systems \& Signal Processing, vol. 27, no. 3, pp. 277-294, May 2008. 